\title{
Spatiotemporal differentiation and the obstacle factors influencing the coupling coordination between economic development and water pollution control capability in the Yangtze River Economic Belt
}

Lelin LV

Hohai University - Jiangning Campus

Canjun Chen ( $\nabla$ canjun951213@163.com )

Hohai University - Jiangning Campus

\section{Zhuofu Wang}

Hohai University - Jiangning Campus

\section{Research Article}

Keywords: Yangtze River Economic Belt, economic development, water pollution control capability, coupling coordination degree, spatiotemporal differentiation, obstacle factors

Posted Date: February 7th, 2022

DOI: https://doi.org/10.21203/rs.3.rs-1263869/v1

License: (9) This work is licensed under a Creative Commons Attribution 4.0 International License. Read Full License 
1 Spatiotemporal differentiation and the obstacle factors influencing the coupling

2 coordination between economic development and water pollution control capability in the Yangtze River Economic Belt

\section{Lelin Lv ${ }^{1,2}$ Canjun Chen ${ }^{1, *}$ Zhuofu Wang ${ }^{1}$}

1. Business School, Hohai University, Nanjing 211100, China.

2. Henan Key Laboratory of Water Environment Simulation and Treatment, Zhengzhou 450045, China.

*Corresponding author: Canjun Chen, E-mail: canjun951213@163.com

Abstract: The Yangtze River Economic Belt (YREB) is a highly influential economic belt and an innovative demonstration belt for the protection and restoration of ecological and environmental systems. The dynamic coordination between economic development system (EDs) and water pollution control capability system (WPCCs) is a critical issue to be solved for regional sustainable development. However, this topic has not been adequately addressed in previous studies. To bridge this gap, this paper analyzed the spatiotemporal differentiation and obstacle factors influencing the coupling coordination between EDs and WPCCs in the Chinese Five-Year Plan based on coupling coordination degree model and obstacle degree model. The main results suggest that: (1) the comprehensive level of the comprehensive level of water pollution control capability presents an upward trend with the increase of economic development. A $J$-shaped relationship existed between the EDs and WPCCs. (2) the regions with rapid economic growth are mainly distributed in the Shanghai, Zhejiang, Jiangsu, Chongqing, and Sichuan. Moreover, water pollution control capability system shows this pattern, eastern regions $>$ western regions $>$ central regions. (3) the coupling coordination level of each region in the YREB has improved from a moderately unbalanced development level to a superiorly balanced development level from 2006 to 2019. (4) per capita gross domestic product, gross product of tertiary industry, total volume of waste water treated, and per daily volume treated of sewage treatment facilities are the major indexes influencing the coordinated development of the EDs and WPCCs. These finding are conductive to formulating reasonable strategies for water environment protection and sustainable development and providing a direction for urban planning.

Keywords: Yangtze River Economic Belt; economic development; water pollution control capability; coupling coordination degree; spatiotemporal differentiation; obstacle factors.

\section{Introduction}

A nice water environment is a crucial foundation for the sustainable development of cities ( $\mathrm{Li}$ et al. 2019; $\mathrm{Li}$ et al. 2020; Zhang et al. 2021). The Yangtze River Economic Belt (YREB), as a watershed economy, involves water, ports, biological, and environment aspects, which must be comprehensively controlled and planned (Cui et al. 
2021; Deng et al. 2021; Zhao et al. 2013). However, the rapid development of the YREB has brought great pressure on the water shortage, water pollution and water ecosystem destruction (Jin et al. 2018; Li et al. 2018; Xu et al. 2020). These problems hinder the coordinated and sustainable development of economic development and water ecology in the YREB. Therefore, the future of the YREB development lies in changing the predatory economic development mode to the sustainable economic development mode.

Economic development of YREB is highly dependent on the water ecological environment (Shi et al. 2020; Zhang and Jiao 2015). The water ecological environment is the material condition for economic development and the basis for human survival, and it can either promote economic development or hinder it (Yang et al. 2020). To maintain the coordinated development of the YREB, Chinese government has issued many policy documents to improve the water pollution control capability of cities, such as, in 2016, the Outline of the Development plan for the Yangtze River Economic Belt was released, emphasizing the establishment of the strictest ecological environment protection and water resources management systems. In 2017, the Plan for ecological and environmental protection along the Yangtze Economic Belt was issued, calling for prioritizing ecological and environmental protection. Overall, in long-term practice and research, people realize the importance of the relationship economic development system (EDs) and water pollution control capability system (WPCCs) in the YREB, and gradually form the coordinated development theory that the two are opposites and unity.

Coupling theory can be used to express the influence degree of interactions between multiple systems (Han et al. 2019; Ai et al. 2016; Li et al. 2012). The coupling coordination degree obtained by calculation can not only clearly reflect the coordination degree, but also judge whether the systems develop harmoniously between the EDs and WPCCs (Yang et al. 2020; Zhang et al. 2021). In the economic development system and water pollution control capability system, the rapid development of economy brings adverse impact on water resources environment. However, the sustainable economic development also provides financial support and technical guarantee for the prevention and management of water pollution (Liu et al. 2019). Conversely, the level of water pollution control capability will also influence the effect of economic development (Zhang and Jiao 2015). Sufficient water resources and quality water quality can ensure high-quality economic development. More importantly, with the deepening of the implementation of the YREB strategy, the interconnectivity between regions is increasing. It has become the key of the sustainable development of the YREB to realize the coordinated development of the EDs and WPCCs in the trans-regional process while maintaining the improvement of water ecological environment. Therefore, exploring the coupling relationship between the EDs and WPCCs has become a significance topic to implement the high-quality development of the YREB. 
The degree of coupling and coordination between the EDs and WPCCs is strongly linked the level of social and economic sustainable development of a country or region. Therefore, in recent years, the focus of scholars has become to improve the coupled and coordinated development, especially economic development system and ecological environment system of the YREB. Peng et al. (2021) constructed the dynamic model of the economy-resourceenvironment of the YREB, and measured and compared the coordinated development levels of the YREB under different resources and environment management and control intensities based on the coupling coordination degree model. Zhang and Liu (2017) analyzed the coupling coordination degree of urbanization system and ecological environment system in the YREB from two dimensions of time and space by using variation coefficient method and coupling measure model. To correctly grasp the relationship between eco-environmental protection and economic development, Long and Yang (2020) constructed an economic development index and carbon emission accounting system to evaluate the economy-ecosystem system of the YREB, and analyzed the spatial differentiation of carbon emissions through spatial autocorrelation. To sum up, only sustainable development of ecological environment protection can continuously optimize the long-term development of YREB. Therefore, to explore the relation between the EDs and WPCCs of the YREB, it is necessary to measure the coupling coordination level of the systems on the spatiotemporal.

Despite these advances in the study of the interaction between economic development and ecological environment, few studies have been conducted from the perspective of water pollution control capability and economic development. Even if there is, it only explored the changes of a single system. In addition, in the previous model of coupling coordination degree (CCD), the contribution coefficient is determined by subjective method (Cai et al. 2021; Deng et al. 2021). Most importantly, previous studies did not explore the obstacles affecting the coordinated development between economic development system and water pollution control capacity system. To fill these gaps, this paper introduces an improved CCD model and obstacle degree model to analyze the spatiotemporal differentiation and obstacle indicators influencing the coupling coordination between the EDs and WPCCs in the YREB.

This study has three main objectives: (1) develop indicator systems for coupling coordination analysis, including economic development system and water pollution control capability system, (2) analyze the coupling coordination level and spatiotemporal differentiation based on the coupling coordination model of the economic development and water pollution control capability systems, and (3) diagnose the main obstacle factors in subsystem and indicator level affecting the coordinated development of systems based on the obstacle degree model.

\section{Materials and Methodology}

\subsection{Study Area}


The YREB covers 11 regions, including Shanghai (SH), Jiangsu (JS), Zhejiang (ZJ), Anhui (AH), Jiangxi (JX), Hubei (HB), Hunan (HN), Chongqing (CQ), Sichuan (SC), Yunnan (YN), and Guizhou (GZ). The YREB is an economic belt with the highest economic density in China, which has unique advantages and huge potential for development. The rapid development of the YREB cannot be promoted without water resources in the region, and water resources are essential elements for the construction of the green ecological of the YREB. However, the development of the YREB is faced with many problems, mainly including the severe water ecological environment situation, unbalanced regional development, and the incomplete regional cooperation mechanism (Qian 2021; Tang et al. 2019). With the continuous development of urbanization, the YREB regions are also constantly improving its ability to maintain water ecological balance, and assuming the responsibility of leading the demonstration belt of ecological civilization construction. Therefore, it is necessary to analyze the coordinated development of economic development and water pollution control capability systems in the YREB.

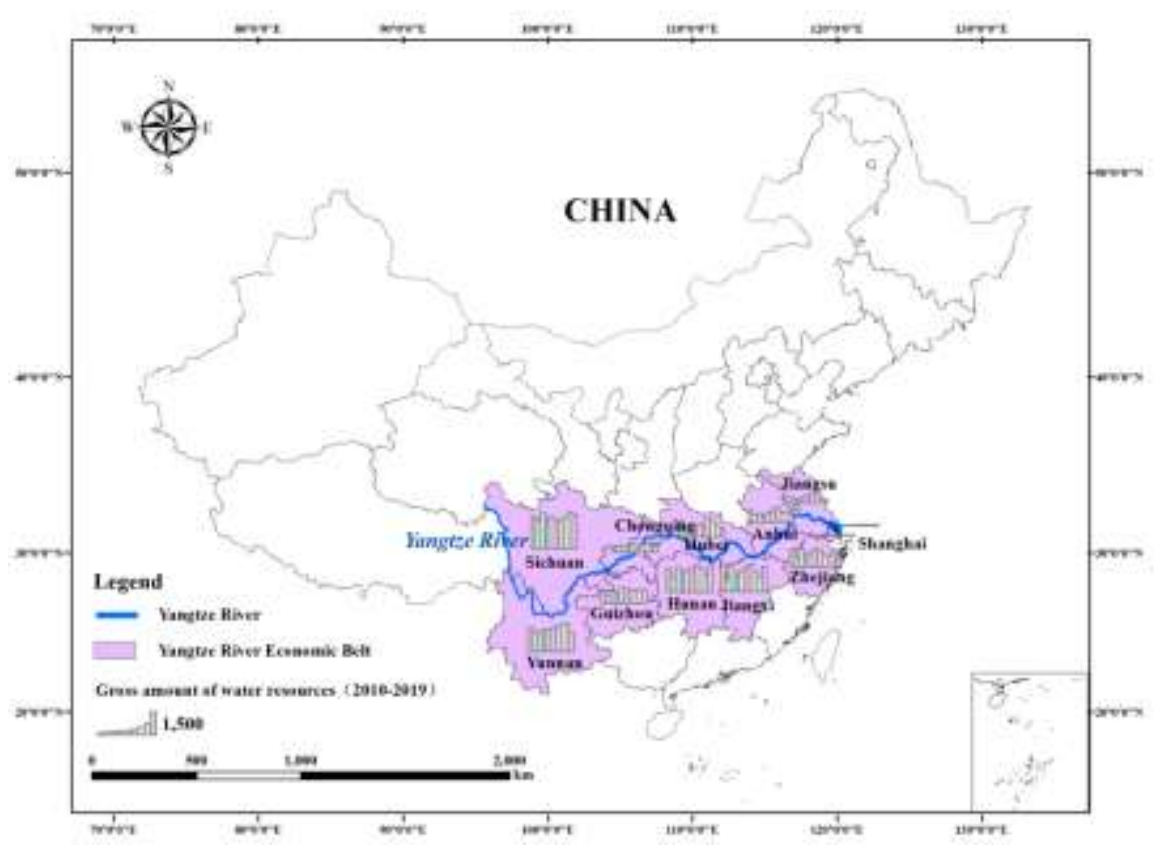

Fig. 1. The Yangtze River Economic Belt regions.

\subsection{Methodology}

A framework is constructed to explore the coordination level and obstacle factors between the EDs and WPCCs for 11 regions of the YREB in the Fig. 2. The main contents are: 1) developing the evaluation index system of economic development and water pollution control capability, 2) collecting the evaluation indicator data and preprocessing, 3) establishing comprehensive assessment model combining AHP-Entropy methods, 4) constructing the improved coupling coordination degree model of economic development and water pollution control capability systems, and 5) establishing the obstacle degree model to analyze and diagnose the major obstacle factors. 


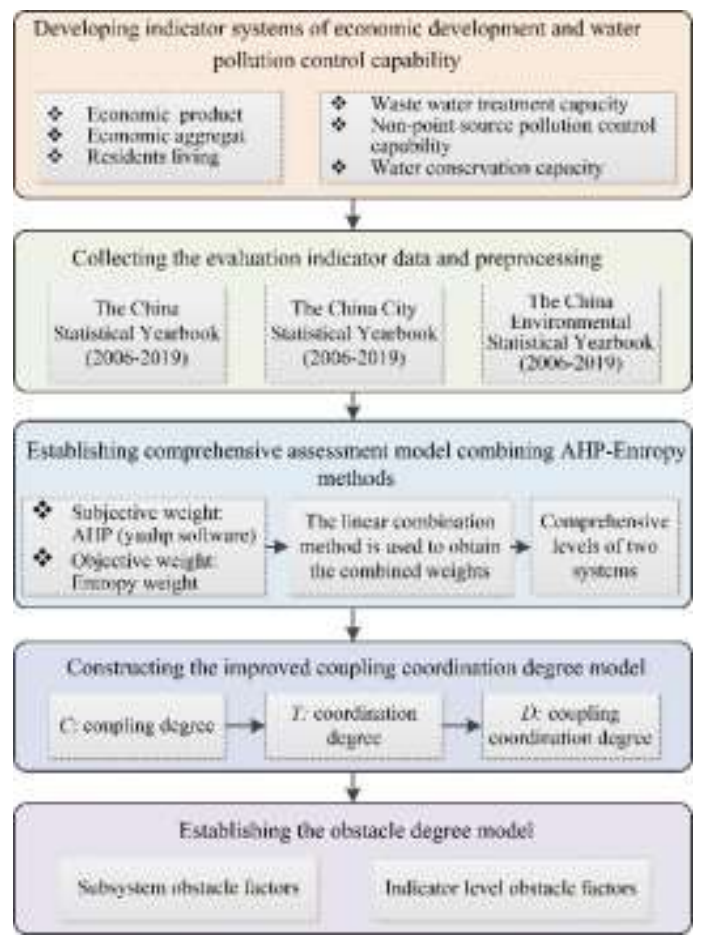

Fig. 2. Framework of the coupling coordination analysis

2.2.1. Evaluation Index of the EDs and WPCCs

Economic development and environment protection are opposites, unity, and coordination (Qian 2021; Yang et al. 2020). There are complex interactions and contradictions between the EDs and WPCCs. Therefore, the EDs and WPCCs can be considered as a coupled system, and the degree of mutual relationship between the two systems can be measured by coupling coordination degree (Fang and Liu 2020; Wang et al. 2020; Zhang and Liu 2017). In light of this, based on the previous studies and the China Environmental Statistical Yearbook, the index systems of economic development and water pollution control capacity were established. Specifically, the economic development system was established from the three dimensions of economic product, economic aggregate, and residents living (Table 1). The water pollution control capability system was established from the three dimensions of economic product, economic aggregate, and residents living (Table 2).

Table 1. Evaluation index system for the economic development.

\begin{tabular}{|c|c|c|c|c|}
\hline Subsystem & Indicator Level & Unit & Nature & References \\
\hline \multirow{4}{*}{$\begin{array}{l}\text { Economic } \\
\text { product }\end{array}$} & Gross product of primary industry (E1) & $10^{8}$ Yuan & + & (Cui et al. 2019; \\
\hline & Gross product of secondary industry (E2) & $10^{8}$ Yuan & + & Ding et al. 2015; \\
\hline & Gross product of tertiary industry (E3) & $10^{8}$ Yuan & + & Han et al. 2021; \\
\hline & Per capita gross domestic product (E4) & $10^{8}$ Yuan & + & $\begin{array}{l}\text { Peng et al. 2020; } \\
\text { Tang et al. 2019) }\end{array}$ \\
\hline \multirow{5}{*}{$\begin{array}{l}\text { Economic } \\
\text { aggregate }\end{array}$} & Total general public budget expenditure (E5) & $10^{8}$ Yuan & + & \\
\hline & Total general public budget revenue (E6) & $10^{8}$ Yuan & + & (Han et al. 2021; \\
\hline & Total investment in fixed assets (E7) & $10^{8}$ Yuan & + & Liao et al. 2019; \\
\hline & Total foreign capital actually utilized (E8) & USD $10^{8}$ Yuan & + & Peng et al. 2020; \\
\hline & Gross import and export (E9) & USD $10^{8}$ Yuan & + & $\begin{array}{l}\text { Tang et al. 2019; } \\
\text { Zhao et al. 2013) }\end{array}$ \\
\hline \multirow{2}{*}{$\begin{array}{l}\text { Residents } \\
\text { living }\end{array}$} & $\begin{array}{c}\text { Annual per capita consumption expenditure of } \\
\text { urban households (E10) }\end{array}$ & Yuan & + & \\
\hline & $\begin{array}{l}\text { Annual per capita consumption expenditure of } \\
\text { rural households (E11) }\end{array}$ & Yuan & + & $\begin{array}{l}\text { (Ding et al. 2015; } \\
\text { Han et al. 2021; }\end{array}$ \\
\hline
\end{tabular}




\begin{tabular}{cccc}
\hline $\begin{array}{c}\text { Annual per capita disposable income of urban } \\
\text { households (E12) }\end{array}$ & Yuan & + & $\begin{array}{c}\text { Liao et al. 2019; } \\
\text { Peng et al. 2020; } \\
\text { Annual per capita net income of rural } \\
\text { households (E13) }\end{array}$ \\
$\begin{array}{c}\text { Yuan et al. 2018) } \\
\text { Engle's coefficient of urban households (E14) }\end{array}$ & $+\%$ & - & \\
Engle's coefficient of rural households (E15) & $\%$ & - & \\
\hline
\end{tabular}

Table 2. Evaluation index system for water pollution control capability.

\begin{tabular}{|c|c|c|c|c|}
\hline Subsystem & Indicator Level & Unit & Nature & References \\
\hline \multirow{5}{*}{$\begin{array}{l}\text { Waste water } \\
\text { treatment capacity }\end{array}$} & Waste water treatment rate $(\mathrm{W} 1)$ & $\%$ & + & \multirow{5}{*}{$\begin{array}{c}\text { (Cui et al. 2019; Gai et } \\
\text { al. 2013; Nie and Zhang } \\
\text { 2020; Peng et al. 2020; } \\
\text { Sun et al. 2018) } \\
\text { China Environmental } \\
\text { Statistical Yearbook }\end{array}$} \\
\hline & Length of drainage pipes (W2) & $\mathrm{km}$ & + & \\
\hline & $\begin{array}{l}\text { Number of waste water treatment plants } \\
\qquad \text { (W3) }\end{array}$ & unit & + & \\
\hline & Total volume of waste water treated (W4) & $10^{4}$ tons & + & \\
\hline & $\begin{array}{l}\text { Per daily volume treated of sewage treatment } \\
\text { facilities (W5) }\end{array}$ & $10^{4}$ tons/day & + & \\
\hline \multirow{5}{*}{$\begin{array}{l}\text { Non-point source } \\
\text { pollution control } \\
\text { capability }\end{array}$} & Consumption of chemical fertilizers (W6) & ton & - & \multirow{6}{*}{$\begin{array}{c}\text { (Deng 2021; Tian and } \\
\text { Chen 2014; Xu et al. } \\
\text { 2020; Zhang and Wang } \\
\text { 2021) } \\
\text { China Environmental } \\
\text { Statistical Yearbook }\end{array}$} \\
\hline & Use of pesticide (W7) & ton & - & \\
\hline & Use of agricultural plastic film (W8) & ton & - & \\
\hline & Use of plastic film for covering plants (W9) & ton & - & \\
\hline & Increased soil erosion control area (W10) & $10^{3}$ ha. & + & \\
\hline \multirow{5}{*}{$\begin{array}{c}\text { Water } \\
\text { conservation } \\
\text { capacity }\end{array}$} & Total volume of water conservation (W11) & $10^{4}$ tons & + & \\
\hline & $\begin{array}{l}\text { Per capita daily household water } \\
\text { consumption (W12) }\end{array}$ & liter & - & \multirow{4}{*}{$\begin{array}{l}\text { (Gai et al. 2013; Nie and } \\
\text { Zhang 2020; Tang et al. } \\
\text { 2019; Xu et al. 2020) } \\
\text { China Environmental } \\
\text { Statistical Yearbook }\end{array}$} \\
\hline & Repeated utilization factor (W13) & $\%$ & + & \\
\hline & $\begin{array}{l}\text { Total amount of water replenished for } \\
\text { ecological environment (W14) }\end{array}$ & $10^{8}$ tons & - & \\
\hline & $\begin{array}{l}\text { Proportion of wetland in total area of } \\
\text { territory (W15) }\end{array}$ & $\%$ & + & \\
\hline
\end{tabular}

125 Note: "+" and "-" represent positive and negative indicators respectively.

\subsubsection{Data Sources and Preprocessing}

In order to guarantee the objectivity and accuracy of the evaluation results, the economic development and water

128 pollution control capability systems index data released by China Statistics Bureau are used in this study, including

129 China Statistical Yearbook (2006-2019), and the China Environmental Statistical Yearbook (2006-2019)

130 (http://www.stats.gov.cn/). The analysis indicators in the economic development and water pollution control

131 capability systems include positive and negative indicators. In order to delete the differences in the data of various

132 indicators, this paper first needs to normalize the original data [55]. If it is a positive indicator, Eq. (1) will be

133 selected to standardize the data. On the contrary, If the variable is a negative indicator, Eq. (2) will be selected.

$$
\begin{aligned}
& \text { Positive indicator: } r_{i j}=\frac{x_{i j}-\min _{j}\left(x_{i j}\right) / 1.05}{1.05 \max _{j}\left(x_{i j}\right)-\min _{j}\left(x_{i j}\right) / 1.05} \\
& \text { Negative indicator: } r_{i j}=\frac{1.05 \max \left(x_{i j}\right)-x_{i j}}{1.05 \max _{j}\left(x_{i j}\right)-\min _{j}\left(x_{i j}\right) / 1.05},
\end{aligned}
$$


Where $x_{i j}$ is the value of $j$ in $i$ years. $r_{i j}$ is the normalized value of $x_{i j} \cdot \max _{j}\left(x_{i j}\right)$ and $\min _{j}\left(x_{i j}\right)$ indicated the maximum and minimum of indicator $j$, respectively. The maximum value multiplied by 1.05 and the minimum value divided by 1.05 are to reduce the heterogeneity caused by boundary effect to interfere with the calculation results (Wen and Wen 2019), $i=1,2, \mathrm{~L}, m, j=1,2, \mathrm{~L}, n$..

\subsubsection{Comprehensive Assessment Combining AHP-Entropy Methods}

In this study, AHP and entropy methods are combined to determine the weight of each index, and finally calculate comprehensive level of the EDs and WPCCs. The detail process is as follows:

Step 1: Determine the subjective weight using AHP method. In this study, yaahp software is used to calculate the objective weight $w_{s w}$ results quickly and conveniently.

Step 2: Determine the objective weight using entropy weight method. The entropy weight $w_{o w}$ of indicators at each level of economic development and water pollution control capability systems, which can be calculated by Eqs. (3) and (4):

$$
\begin{gathered}
G_{j}=-\frac{1}{\ln m} \sum_{i=1}^{m}\left(F_{i j} \ln F_{i j}\right) \\
w_{o w}=\left(1-G_{j}\right) / \sum_{j=1}^{m}\left(1-G_{j}\right)
\end{gathered}
$$

of the $j$ th evaluation indicator. $w_{o w}$ is the weight of the indicator. $m$ is the number of years.

Step 3: Determine the weight based on AHP-Entropy methods. This study used the linear combination method (Jiang et al. 2011; Nabavi-Kerizi et al. 2010) to obtain the combined weight of economic development and water pollution control capability systems indexes. In order to eliminate the interference of large fluctuation data and make the difference between $w_{s w}$ and $w_{o w}$ consistent with the difference between $\eta$ and $\phi$, the concept of distance function is introduced (Zhang et al. 2011). The combined weight can be expressed as follows:

$$
w_{A E}=\eta w_{s w}+\phi w_{o w}
$$

Where $\eta$ and $\phi$ are the distribution coefficients of weights, $\eta+\phi=1$.

The distance function of subjective weight and objective weight can be expressed as: 


$$
d\left(w_{s w}, w_{o w}\right)=\left[\frac{1}{2} \sum_{i=1}^{n}\left(w_{s w}-w_{o w}\right)^{2}\right]^{\frac{1}{2}}
$$

155

The difference between the partition coefficients of weights can be expressed as:

$$
D=|\eta-\phi|
$$

Therefore, according to the Eqs. (6) and (7), the simultaneous equations are constructed as follows:

$$
\left\{\begin{array}{c}
d\left(w_{s w}, w_{o w}\right)^{2}=(\eta-\phi)^{2} \\
\eta+\phi=1
\end{array}\right.
$$

Then, the partition coefficients $\eta, \phi$ of weights can be obtained, and substitute the distribution coefficients into Eq. (5). Finally, the combined weight $w_{A E}$ of indicators at each level of water pollution control capability system and economic development system can be obtained.

Step 4: Calculate comprehensive level of the EDs and WPCCs. According to the normalized value and weight of each indicator, the comprehensive level of the EDs and WPCCs were calculated by weighted summation. Therefore, comprehensive level of the EDs and WPCCs in $i$ year can be expressed as follows:

$$
\begin{gathered}
f_{i j}(E D)=w_{A E-j}^{e} \times r_{i j}^{e} \\
f_{i j}(W P C C)=w_{A E-j}^{w} \times r_{i j}^{w}
\end{gathered}
$$

Where $f_{i}(E D)$ and $f_{i}(W P C C)$ represent the comprehensive level of economic development and water pollution control capability systems in $i$ years, respectively. $w_{A E-j}^{e}$ and $r_{i j}^{e}$ represent the weight and the normalized value of the economic development system, respectively. $w_{A E-j}^{w}$ and $r_{i j}^{w}$ represent the weight and the normalized value of the water pollution control capability system, respectively. In addition, $n$ is the number of indicators.

\subsubsection{Improved Coupling Coordination Degree Model}

The contribution coefficient of CCD model is determined by subjective method in the previous studies (Ding et al. 2015; Liu et al. 2018). In order to calculate the coupling coordination degree more accurately and objectively, this study proposes an improved CCD model based on the synergy theory (Brereton 1978). The calculation steps are shown as follows:

$$
\alpha=\frac{f(E D)}{f(W P C C)+f(E D)}
$$




$$
\beta=\frac{f(W P C C)}{f(W P C C)+f(E D)}
$$

$\frac{\text { Classes }}{\text { Balanced development }}$

Transitional development

Unbalanced development

Table 3. Classification standard of CCD values

$$
\begin{gathered}
C=\frac{\sqrt{f(W P C C) \times f(E D)}}{(f(W P C C)+f(E D)) / 2} \\
T=\alpha f(W P C C)+\beta f(E D) \\
D=\sqrt{C \times T}
\end{gathered}
$$

Where $C$ is the coupling degree between the EDs and WPCCs, which reflects the strength of the connections between the EDs and WPCCs. $T$ is the coupling coordination index between the EDs and WPCCs. $D$ is the coupling coordination degree the EDs and WPCCs.

To clearly describe the CCD level between water pollution control capability system and economic development system, this study classified the coupling coordination degree grade. According to the results of $f(W P C C)$ and $f(E D)$, the CCD values are divided into 3 categories and 6 levels in this paper with reference (Zhang and Li 2020). The coupling coordination states are shown in Table 3.

\subsubsection{Obstacle Degree Model}

The obstacle degree model is introduced to analyze and diagnose the obstacle factors that influence the CCD value between the water pollution control capability and economic development (Luo et al. 2019; Wu et al. 2015). The analysis results of obstacle factors are helpful for the government to adjust the direction of water pollution control and formulate new prevention measures and policies. The model includes three basic variables: factor contribution degree, factor skewness, and factor obstacle degree. The obstacle degree model can be expressed as follows: 


$$
O_{j}=\frac{\left(1-r_{i j}\right) w_{A E}}{\sum_{j=1}^{n}\left(1-r_{i j}\right) w_{A E}}
$$

In this study, factor contribution degree is the index weight $w_{A E}$. Factor skewness is replaced by the difference between 1 and the normalized value $r_{i j}$. Factor obstacle degree $O_{j}$ denotes the effect degree of subsystems or indicators on CCD value between the economic development and water pollution control capability systems.

\section{Results}

3.1. Comprehensive levels of economic development and water pollution control capability systems

The variation trend in the comprehensive levels of economic development system for YREB regions from 2006 to 2019 are shown in Fig. 3. The comprehensive levels of economic development system can be obtained through Eq.(9) and the collected data of 11 YREB regions. As shown in Fig. 3a, the comprehensive levels of economic development system were gradually increasing trend in the 11 YREB regions. Specifically, the comprehensive economic development levels of Shanghai, Zhejiang, and Chongqing were higher than that of other regions. This is because the three provinces are coastal regions or municipality (Jiang et al. 2019). Fig. $3 \mathrm{~b}$ revealed the evolution path of economic development for entire YREB from 2006 to 2019 by the three subsystems that constitute the system. Overall, the comprehensive levels of three subsystems have shown a significantly upward trend, which indicated that economic development level of YREB has continued to increase.

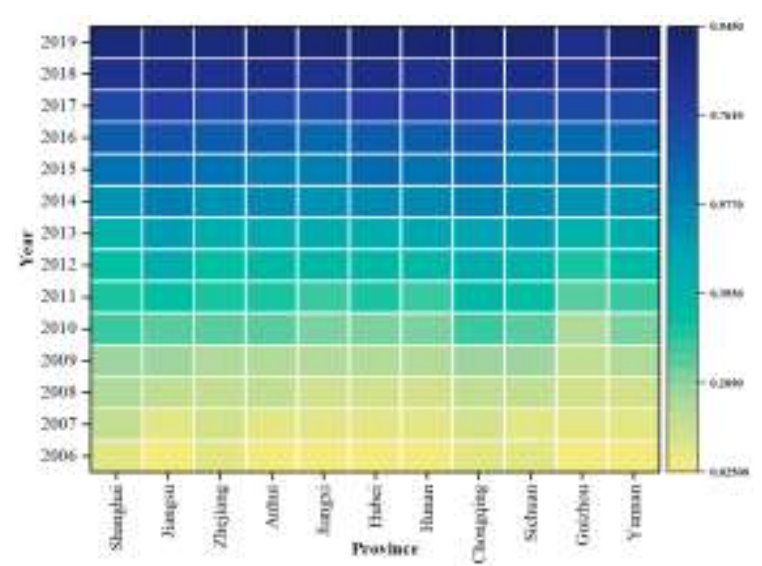

(a) trend in economic development system for each region

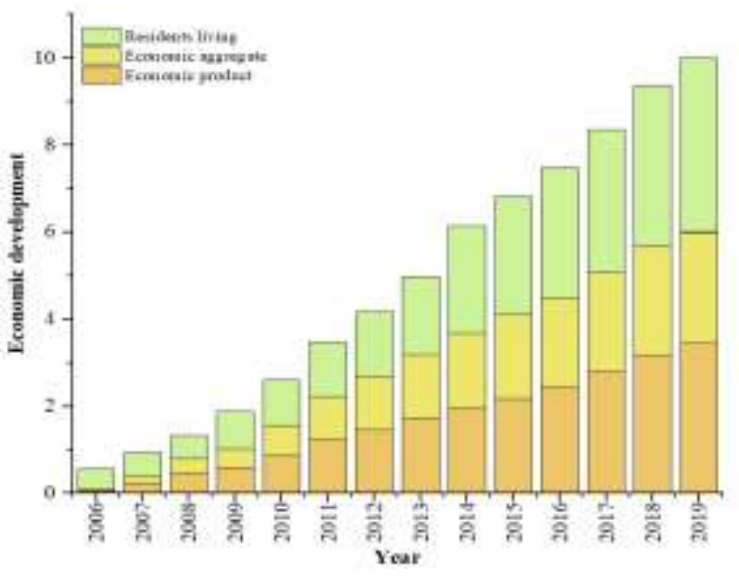

(b) trend in three subsystems for entire YREB

Fig. 3. Comprehensive levels of economic development system for YREB regions from 2006 to 2019.

Fig. 4 illustrated the dynamic changes of water pollution control capability and the level of their subsystem from 2006 to 2019. The comprehensive levels of water pollution control capability system can be obtained through Eq.(10) and the collected data of 11 YREB regions. The comprehensive levels of water pollution control capability system showed a trend of fluctuating growth in Fig. 4a. Obviously, Shanghai province has the fastest 

to 0.68 in 2019. Moreover, except for the obvious fluctuation of Anhui, Jiangxi and Guizhou provinces, the growth level of water pollution control capability in other regions is relatively consistent. Fig. $4 \mathrm{~b}$ depicted the changing trend of water pollution control capability for entire YREB from 2006 to 2019 by the three subsystems that constitute the system. The three subsystems of water pollution control capability showed different trends. The comprehensive level of waste water treatment capacity increased from 0.40 in 2006 to 5.11 in 2019 . However, the comprehensive level of non-point source pollution control capability and water conservation capacity subsystems capability in YREB have shown an upward trend but fluctuated in different degrees during the period.

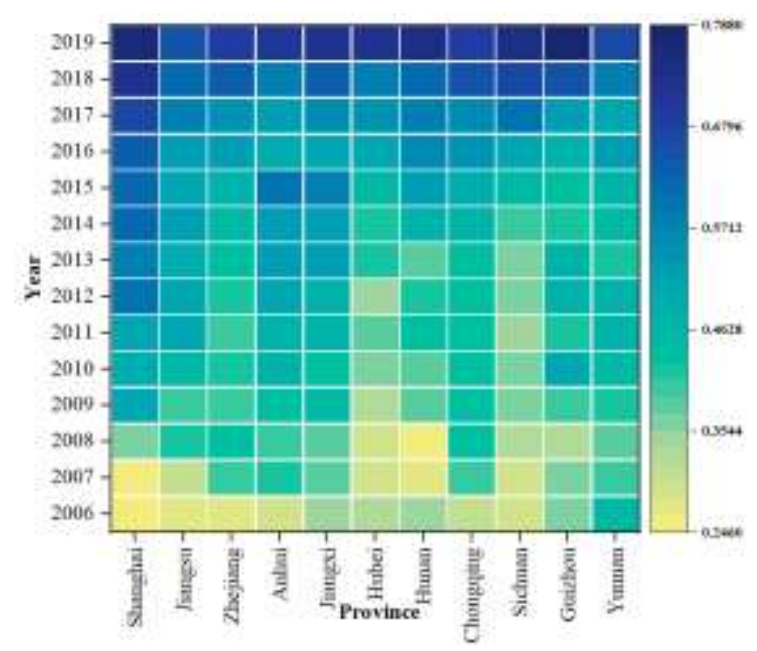

(a) trend in water pollution control capability system for each region

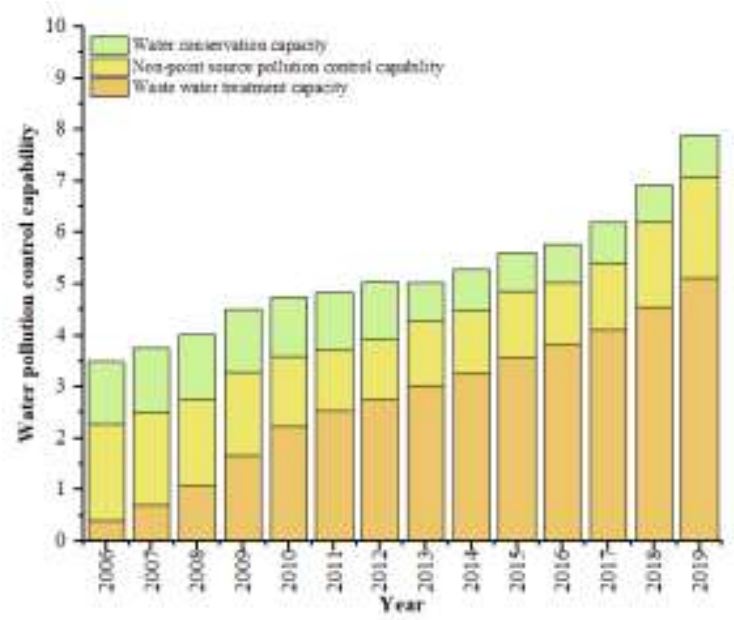

(b) trend in three subsystems for entire YREB

Fig. 4. Comprehensive levels of water pollution control capability system for YREB regions from 2006 to 2019.

To further analysis the relationship between the EDs and WPCCs in 11 regions of the YREB from 2006 to 2019, nonlinear fitting is made for these two systems in Fig. 5. Obviously, there is a $J$-shaped curve relationship Hunan, and Sichuan provinces are more than 0.90. The R-Square and Adj. R-Square values of Zhejiang, Jiangxi, and Chongqing provinces are between 0.80 and 0.90. The R-Square and Adj. R-Square values of Shanghai, Jiangsu, Anhui, Guizhou, and Yunnan provinces are between 0.60 and 0.80 . These results showed that the fitting accuracy is good. Overall, with the rapid development of economy, the comprehensive level of water pollution control capability presented an upward trend. 


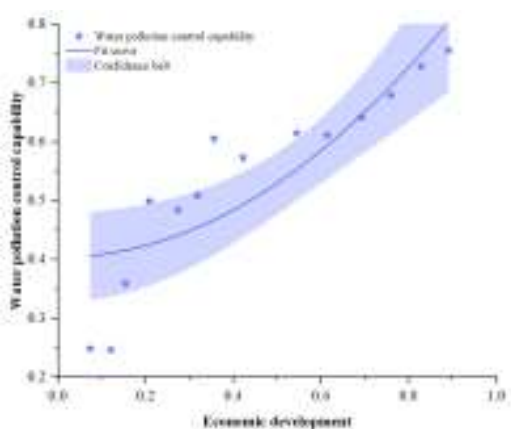

(a) Shanghai

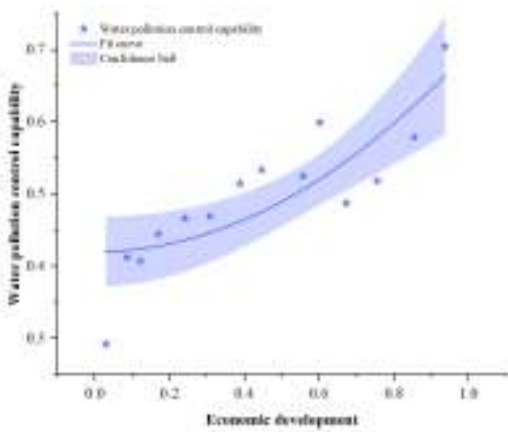

(d) Anhui

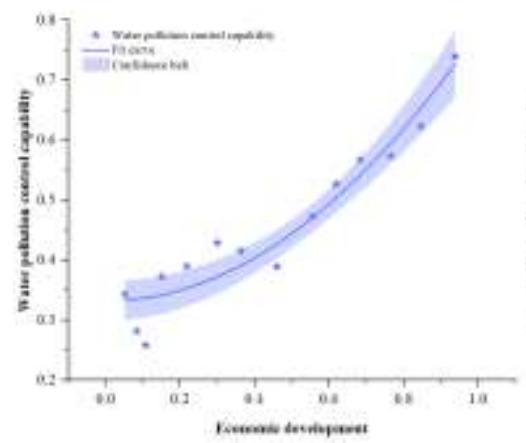

(g)Hunan

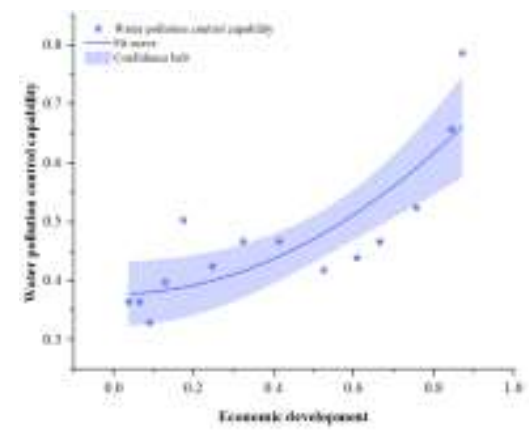

(j) Guizhou

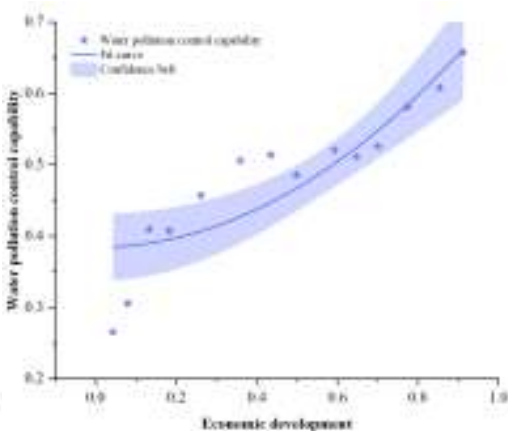

(b) Jiangsu

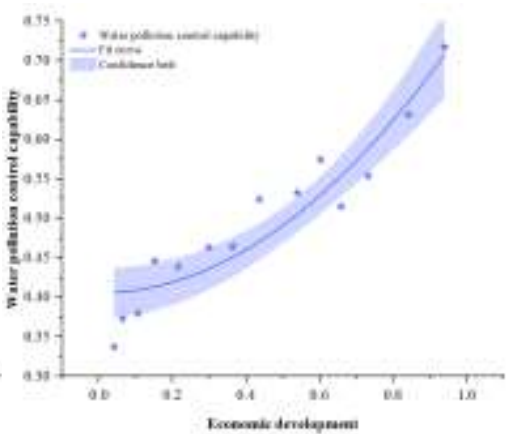

(e) Jiangxi

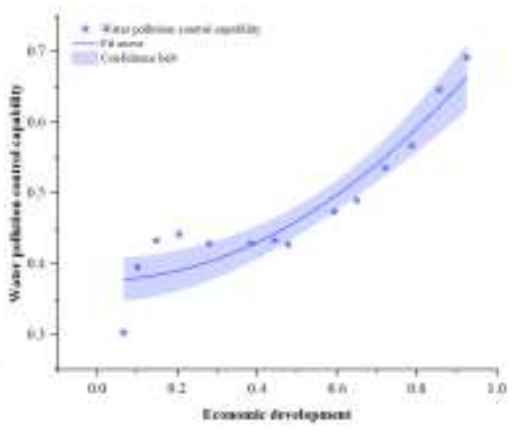

(h) Chongqing

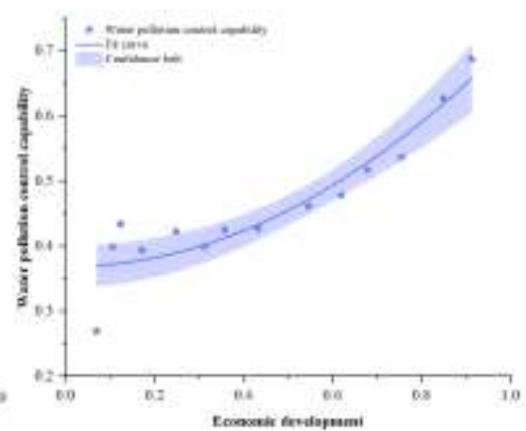

(c) Zhejiang

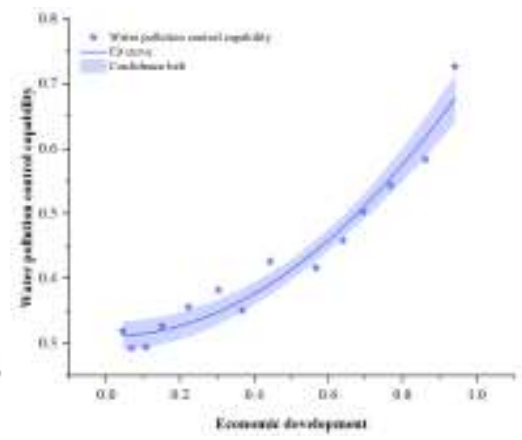

(f) Hubei

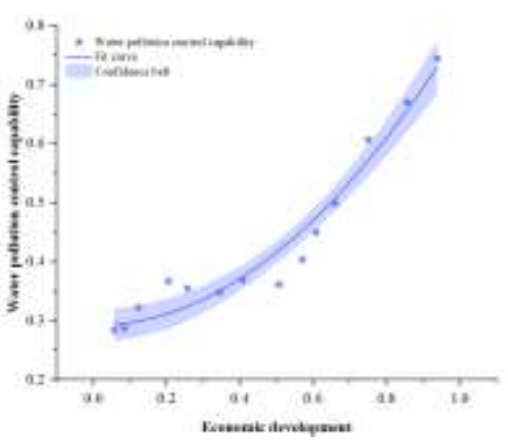

(i)Sichuan

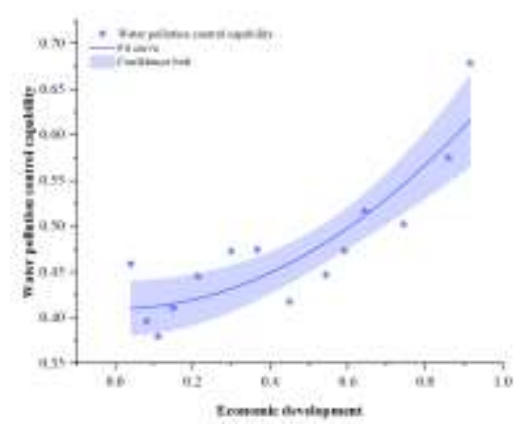

(k) Yunnan

Fig. 5. The fitting curves of economic development and water pollution control capability systems 3.2. Spatiotemporal differentiation of Coupling Coordination Degree

The CCD values are obtained according to the comprehensive level of economic development and water pollution control capacity systems and the improved coupling coordination degree model. Fig. 6 showed variation trend in CCD values between economic development and water pollution control capability systems in 2006-2019. Obviously, CCD values in 11 regions of the YREB increased year by year during the 14 years. 


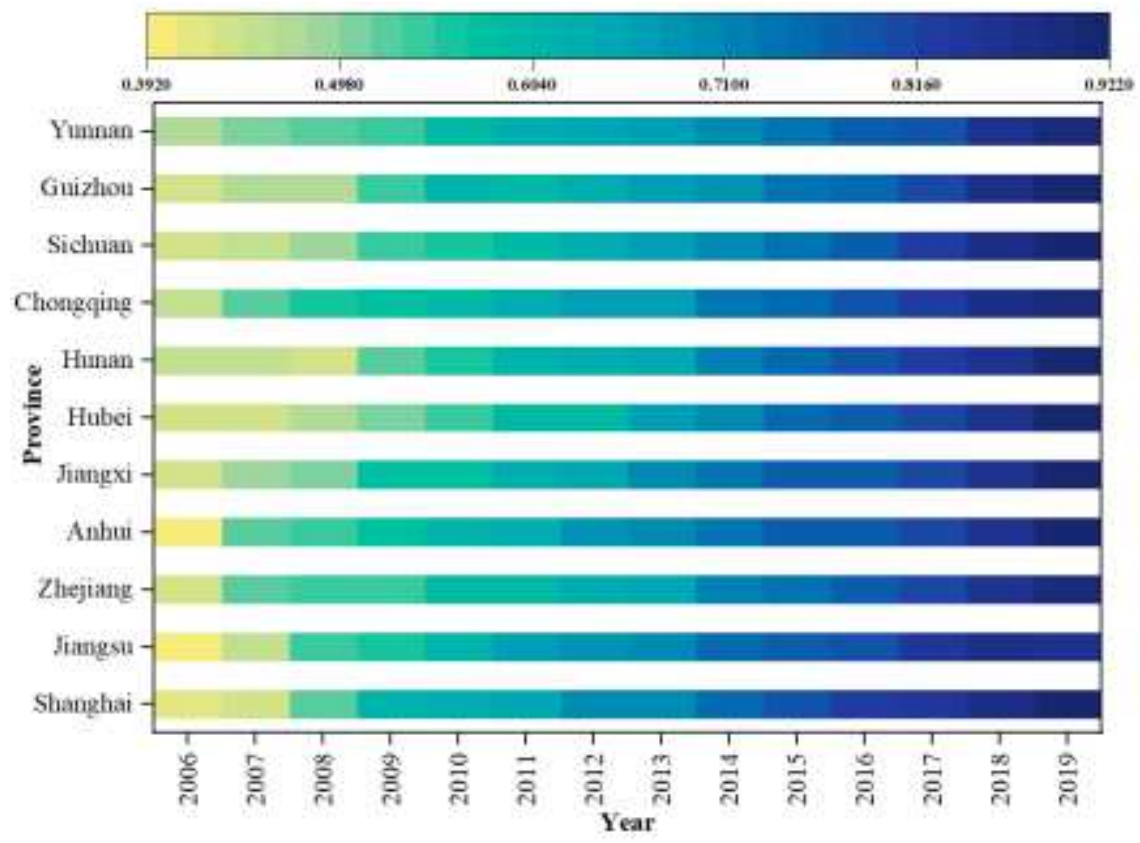

Fig. 6. Variation trend in CCD values between economic development and water pollution control capability systems in 2006-2019.

According to the Chinese Five-Year Plan, the 14 years from 2006 to 2019 are divided into three periods: 2006-2010, 2011-2015, and 2016-2019 in this study. Then, this study conducted a spatial-temporal coupling analysis on $\mathrm{CCD}$ values of the 11 regions of the YREB in these three periods. Based on the classification standard of CCD values between water pollution control capability and economic development systems in Table 3 , this study classified the CCD values into 3 categories and 6 levels. In order to depict the changes more visually in spatial distribution of CCD values in various regions, ArcGIS software is used for spatial-temporal analysis in this paper. The variation trend of the CCD values in the three Five-Year Plan is as follows:

The Eleventh Five-Year Plan period (2006-2010): Fig. 7(a)-(b) showed variation trend in spatial distributions of CCD values in years 2006 and 2010. In 2006, only Anhui province experienced moderately unbalanced development state, while the coordination level in the other 10 regions of the YREB were in the barely unbalanced development state. In 2010, most of the CCD classes of the two systems were at a transitional development. The coordination levels of Yunnan, Sichuan, Jiangxi, Hubei, Hunan, and Zhejiang provinces were in a slightly balanced development state. Moreover, the coordination levels of Shanghai, Jiangsu, Anhui, Guizhou, and Chongqing provinces increased rapidly and were in a favorably balanced development state. Overall, the CCD classes of economic development and water pollution control capability systems started at an unbalanced development level, but then gradually increased in the Eleventh Five-Year Plan.

The Twelfth Five-Year Plan period (2011-2015): Fig. 7(c)-(d) showed variation trend in spatial distributions of CCD values in years 2011 and 2015. In 2011, the coordination levels of eight provinces were in a favorably balanced development state. Moreover, the provinces with slightly balanced development state between the EDs 
and WPCCs were mainly distributed in the middle and upper reaches of the Yangtze River Basin. In 2015, it is

obvious that the coordination levels of all regions were in a favorably balanced development state. Overall, compared with the Eleventh Five-Year Plan, the link between the economic development and water pollution control capability systems showed a significant improvement, and the coordination levels between the two systems improved steadily.

The thirteenth Five-Year Plan period (2016-2019): Fig. 7(e)-(f) showed variation trend in spatial distributions of CCD values in years 2016 and 2019. In 2016, obviously, there is no change in other regions except Chongqing and Shanghai provinces, where the coordination levels turned the favorably balanced development state into the superiorly balanced development state. In 2019, the coordination levels of all regions were in a superiorly 275 balanced development state. During the thirteenth Five-Year Plan period, the performance levels of both the EDs and WPCCs gradually increased, and the coordination state of the two systems changed from transitional development to balanced development.

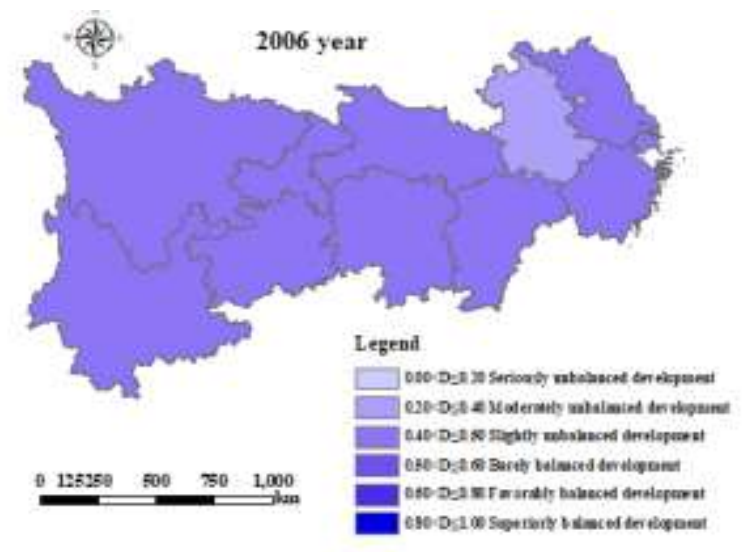

(a) 2006 year

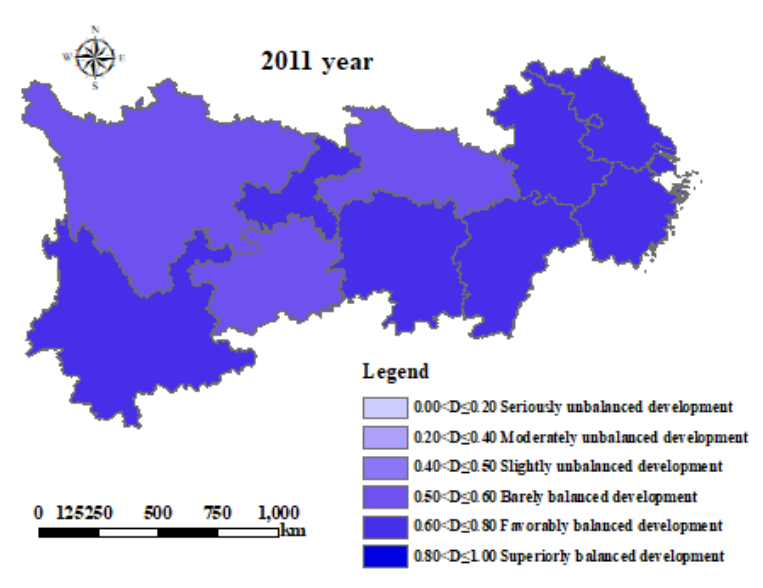

(c) 2011 year

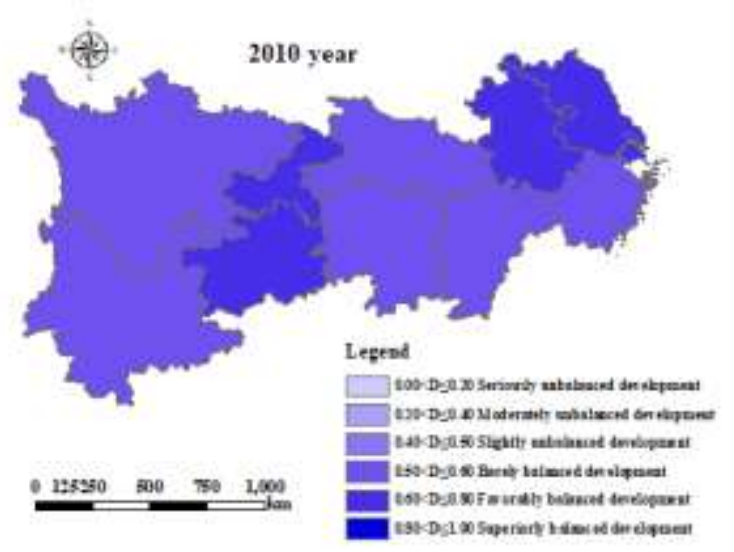

(b) 2010 year

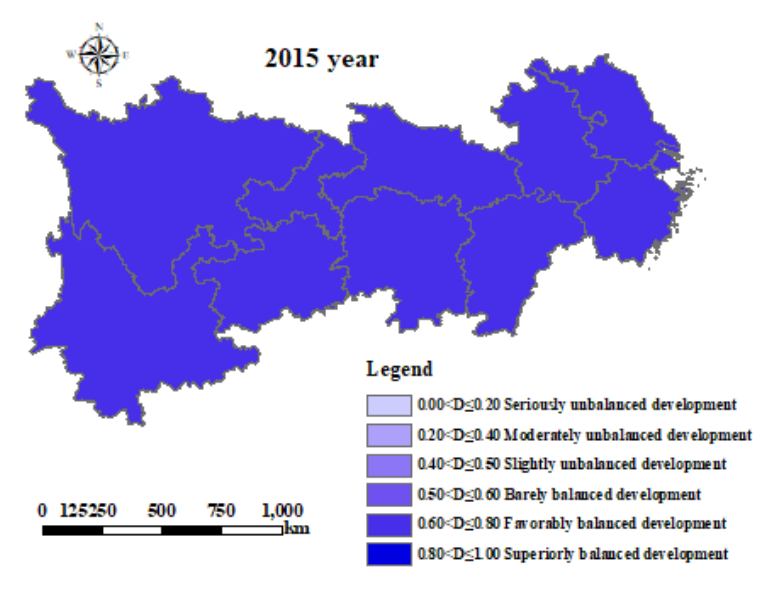

(d) 2015 year 


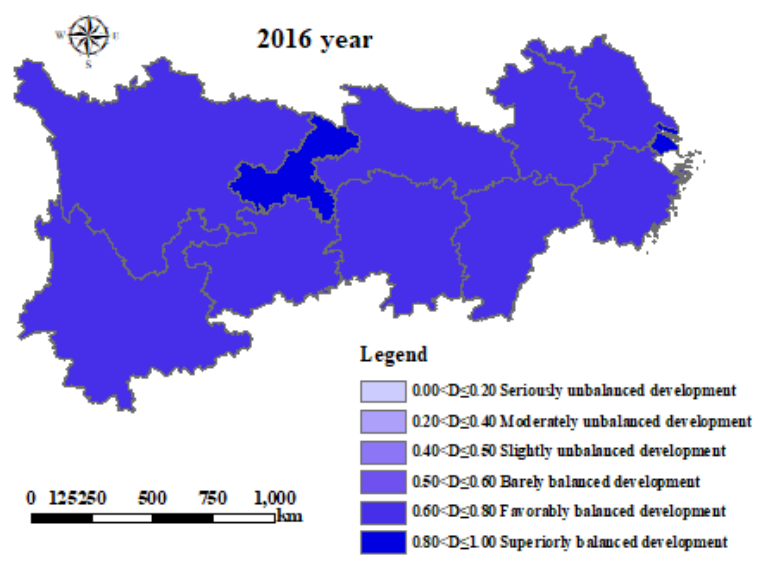

(e) 2016 year

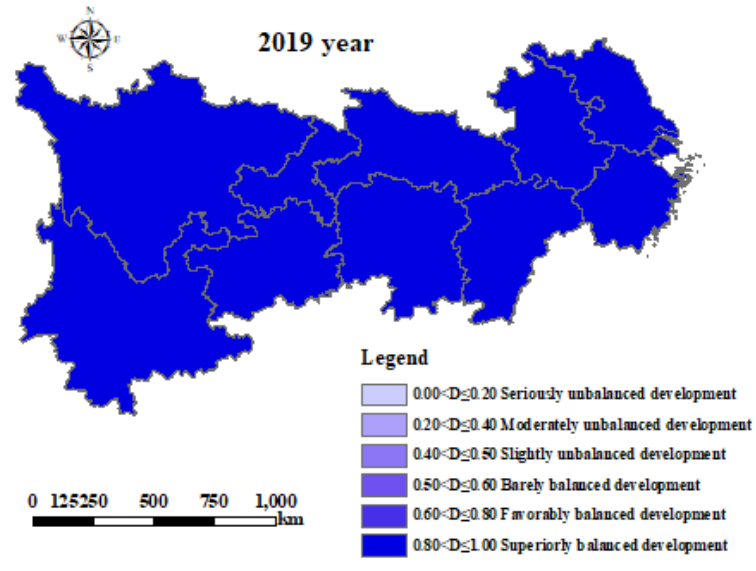

(f) 2019 year

Fig. 7. Variation trend in spatiotemporal differentiation of CCD values during the Eleventh, Twelfth, and Thirteenth Five-Year Plan

\subsection{Major Obstacle Factors of Coupling Coordination Degree}

\subsubsection{Subsystem Obstacle Factors}

The variation trend in factor obstacle degree of economic development subsystems for 11 regions during the three Five-Year Plan period was shown in Fig. 8. The economic development system includes three subsystems: economic product, economic aggregate, and residents living. Overall, in these three periods, the economic product subsystem has the largest obstacle degree, and the resident living subsystem has the smallest obstacle degree, and the two subsystems have little fluctuation (except Shanghai). The subsystem of economic aggregate fluctuated greatly. Moreover, during the Thirteenth Five-Year Plan, the obstacle degree of economic aggregate subsystem in Jiangsu and Guizhou provinces is lower than that of resident living subsystem. To sum up, in the economic development system, economic product is the key subsystem that affects the coordination level of the 11 regions.

Fig. 9 showed the variation trend in factor obstacle degree of water pollution control capability subsystems for 11 regions during the Five-Year Plan. The water pollution control capability system includes three subsystems: waste water treatment capacity, non-point source pollution control capability, and water conservation capacity. There are significant differences in the obstacle degree changes of the three subsystems on the comprehensive level of water pollution control capability in the 11 regions. Specifically, during the Eleventh Five-Year Plan, the waste water treatment capacity subsystem and the water conservation capacity subsystem has the largest and the smallest obstacle degree for all regions, respectively. During the Twelfth Five-Year Plan, the obstacle degree of the wastewater treatment capacity subsystem decreased greatly but non-point source pollution control capability subsystem increased greatly in all regions, especially in Anhui and Yunnan provinces. During the Thirteenth FiveYear Plan, the obstacle degree of the three subsystems fluctuated greatly in each region. Compared to the Eleventh and Twelfth Five-Year Plan, the biggest change is that the biggest obstacle affecting the coordination 
level of the system has changed from waste water treatment capacity subsystems to non-point source pollution control capability subsystems.

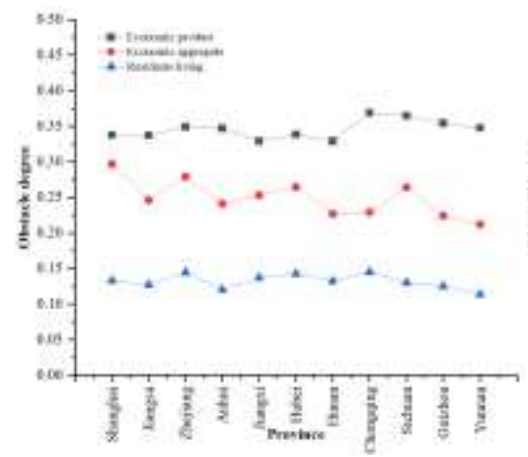

(a) $2006-2010$

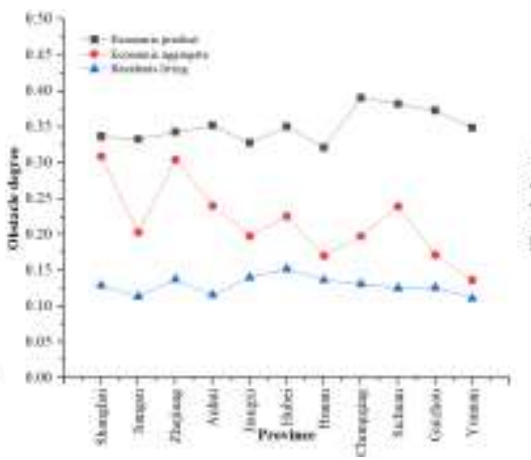

(b) 2011-2015

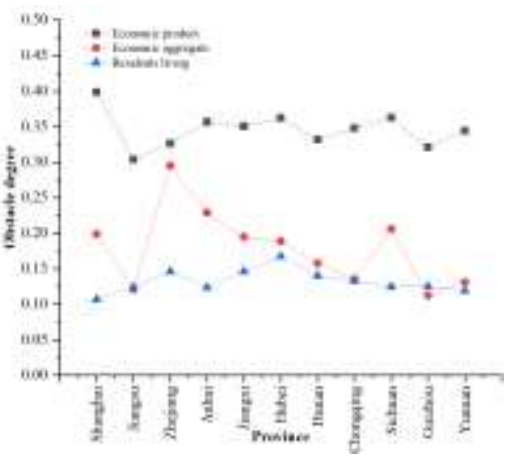

(c) 2016-2019

Fig.8. Variation in factor obstacle degree of economic development subsystems for YREB regions during the Eleventh, Twelfth, and Thirteenth Five-Year Plan

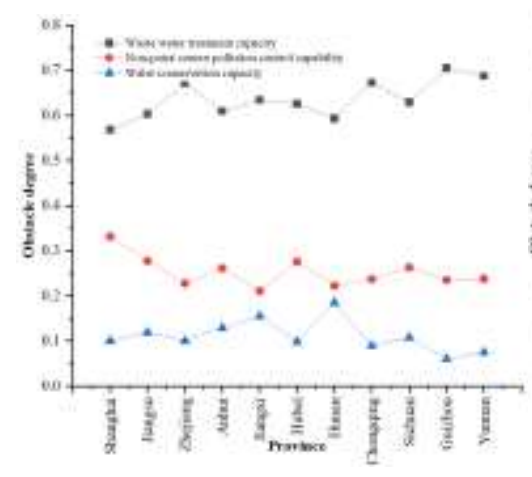

(a) 2006-2010

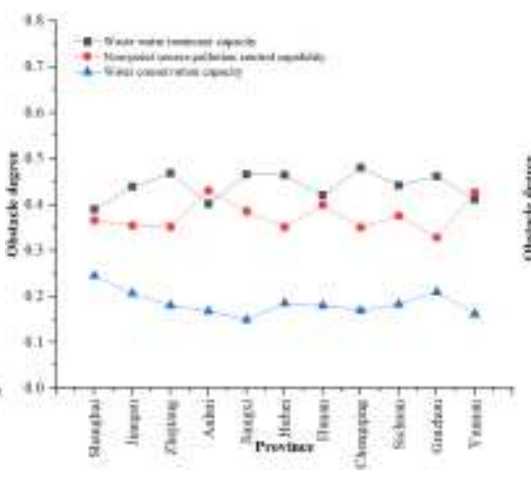

(b) 2011-2015

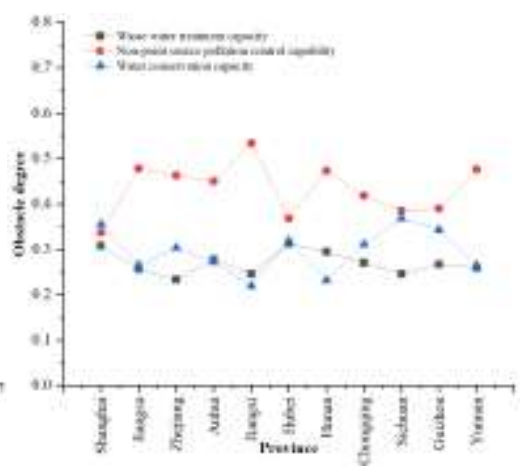

(c) 2016-2019

Fig. 9. Variation in factor obstacle degree of water pollution control capability subsystems for YREB regions during the Eleventh, Twelfth, and Thirteenth Five-Year Plan

\subsubsection{Indicator Level Obstacle Factors}

According to the obstacle degree of each indicator, this study only listed the top five main obstacle indicators of economic development and water pollution control capability systems for analysis. During the calculation process, it is found that the obstacle degree factors of the top five in each region in each Five-Year Plan changed slightly. Therefore, this study is not divided into three periods for analysis here. Tables 4 and 5 list the major obstacle indicators (OI) and contribution degree (CD) to economic development and water pollution control capability systems respectively.

As shown in Table 4, in the economic development system, obstacle degree of the gross product of tertiary industry (E3), per capita gross domestic product (E4), annual per capita disposable income of urban households (E12) in the 11 regions have always been in the top three, and the CD of these three indicators is close to $35 \%$. Total general public budget expenditure (E5), total investment in fixed assets (E7), total foreign capital actually utilized (E8), annual per capita net income of rural households (E13), and Engle's coefficient of urban households (E14) appeared in the fourth or fifth place in turn. From the frequency of occurrence, E7 have a greater impact on 
economic development performance. Moreover, two indicators of economic product subsystem ranked in the top

331 five, which also indicated that this subsystem is one of the main obstacle systems affecting land use performance

332 in these regions, and it is basically consistent with the analysis of each subsystem obstacle degree in Fig. 8.

As shown in Table 5, compared with the economic development system, the top five obstacle indicators in

334 the water pollution control capability system have a greater variation. However, in general the OI of top five

335 ranked are mainly concentrated in the two subsystems of waste water treatment capacity and non-point source

336 pollution control capability, and the $\mathrm{CD}$ of these indicators is close to $50 \%$. Specifically, obstacle degree of per

337 daily volume treated of sewage treatment facilities (W5) in the 11 regions have always been in the top one.

338 Meanwhile, it can be found that the top five obstacle factors in each region all have total volume of waste water

339 treated (W4). From the frequency of occurrence, waste water treatment rate (W1), length of drainage pipes (W2),

340 and increased soil erosion control area (W10) also have great influence on water pollution control capability

341 performance. Overall, indicators in these two subsystems have the greatest impact on the water pollution control

342 capability system of the YREB regions, which is basically consistent with the analysis of the obstacle degree of

343 each subsystem in Fig. 9.

Table 4. The major obstacle indicators in economic development system

\begin{tabular}{|c|c|c|c|c|c|c|c|c|c|c|}
\hline System & \multicolumn{10}{|c|}{ Economic development } \\
\hline \multirow{2}{*}{ Indicator rank } & \multicolumn{2}{|c|}{1} & \multicolumn{2}{|c|}{2} & \multicolumn{2}{|c|}{3} & \multicolumn{2}{|c|}{4} & \multicolumn{2}{|c|}{5} \\
\hline & OI & $\mathrm{CD}$ & $\mathrm{OI}$ & $\mathrm{CD}$ & OI & $\mathrm{CD}$ & $\mathrm{OI}$ & $\mathrm{CD}$ & OI & $\mathrm{CD}$ \\
\hline SH & E4 & 14.57 & E3 & 11.61 & E12 & 11.03 & E14 & 8.73 & E13 & 7.32 \\
\hline JS & E4 & 12.77 & E3 & 11.58 & E12 & 10.79 & E7 & 8.94 & E14 & 7.85 \\
\hline $\mathrm{ZJ}$ & E4 & 12.52 & E3 & 12.26 & E12 & 10.55 & E7 & 8.74 & E5 & 7.59 \\
\hline $\mathrm{AH}$ & E3 & 12.63 & E4 & 12.52 & E12 & 10.14 & E7 & 7.13 & E13 & 6.55 \\
\hline $\mathrm{JX}$ & E3 & 12.59 & E4 & 11.93 & E12 & 9.61 & E7 & 9.36 & E14 & 7.00 \\
\hline HB & E4 & 12.57 & E3 & 12.34 & E12 & 9.92 & E14 & 7.27 & E7 & 6.57 \\
\hline $\mathrm{HN}$ & E3 & 12.02 & E4 & 11.83 & E12 & 10.13 & E7 & 7.72 & E13 & 6.35 \\
\hline CQ & E4 & 13.03 & E3 & 12.69 & E12 & 11.06 & E13 & 6.92 & E7 & 6.89 \\
\hline $\mathrm{SC}$ & E3 & 13.75 & E4 & 13.17 & E12 & 10.41 & E13 & 7.09 & E7 & 6.94 \\
\hline GZ & E4 & 12.45 & E3 & 11.30 & E12 & 9.63 & E7 & 7.55 & E8 & 7.06 \\
\hline YN & E4 & 12.02 & E3 & 11.66 & E12 & 9.74 & E8 & 8.26 & E7 & 7.80 \\
\hline
\end{tabular}

Table 5. The major obstacle indicators in water pollution control capability system

\begin{tabular}{cccccccccccc}
\hline System & \multicolumn{10}{c}{ Water pollution control capability } \\
\hline \multirow{2}{*}{ Indicator rank } & \multicolumn{1}{c}{1} & \multicolumn{9}{c}{2} & \multicolumn{3}{c}{4} & & \multicolumn{3}{c}{5} \\
\cline { 2 - 11 } & OI & CD & OI & CD & OI & CD & OI & CD & OI & CD \\
\hline SH & W5 & 18.40 & W1 & 10.25 & W8 & 8.45 & W10 & 7.38 & W4 & 7.36 \\
JS & W5 & 19.75 & W1 & 9.76 & W10 & 9.24 & W4 & 7.49 & W9 & 7.10 \\
ZJ & W5 & 21.97 & W4 & 8.48 & W1 & 7.94 & W2 & 7.42 & W11 & 7.36 \\
AH & W5 & 19.94 & W10 & 12.19 & W4 & 8.77 & W2 & 7.13 & W7 & 7.05 \\
JX & W5 & 21.73 & W4 & 7.73 & W7 & 7.51 & W2 & 7.48 & W1 & 7.44 \\
HB & W5 & 23.46 & W4 & 9.14 & W10 & 8.77 & W1 & 7.85 & W11 & 7.28 \\
HN & W5 & 19.62 & W4 & 8.64 & W10 & 8.57 & W1 & 7.68 & W11 & 7.61 \\
CQ & W5 & 24.72 & W4 & 8.54 & W2 & 8.09 & W10 & 7.85 & W8 & 6.72 \\
SC & W5 & 20.34 & W10 & 8.68 & W4 & 8.05 & W1 & 7.99 & W2 & 7.55 \\
GZ & W5 & 22.68 & W2 & 8.96 & W4 & 8.57 & W7 & 7.02 & W1 & 6.52 \\
YN & W5 & 19.46 & W10 & 9.33 & W4 & 8.72 & W2 & 7.91 & W7 & 7.62 \\
\hline
\end{tabular}




\section{Discussion}

\subsection{Comprehensive Level Characteristics Analysis}

Due to the unique regional characteristics of the YREB, this study divided the 11 regions of the YREB into eastern (SH, ZJ, and JS), western (CQ, SC, GZ, and YN), and central (HB, HN, JX, and AH) regions for in-depth discussion according to the natural geographical location (Tang et al. 2019; Tang et al. 2020). The YREB has made remarkable achievements and its economic status in China has been rising (Li et al. 2020). According to the analysis for the comprehensive level of economic development system in 11 regions of the YREB, it is obvious that the comprehensive level showed a gradually increasing trend. Specifically, the economic development of the 11 regions showed the pattern of emphasis to the east (Yao 2018). The regions with faster comprehensive level growth of the YREB are mainly distributed in the Yangtze River Delta (Shanghai, Zhejiang, Jiangsu), the central cities (Chongqing) and the provinces where important cities are located (Sichuan). In terms of geographical location, Shanghai, Zhejiang, and Jiangsu are located at the intersection of the rivers and the seas, and there are many coastal ports along the river, so the economy started faster than other regions (Miao and Sun 2020; Zhao et al. 2013). Chongqing and Chengdu in Sichuan province are the Chengdu-Chongqing Area Twin-City Economic Circle in China, adjacent to the Three Gorges Reservoir area in the east. Factors of production such as labor and capital are more advantageous, so the economic development is growing faster than other regions (Pan et al. 2021; Pan et al. 2021; Sun and Luo 2021). On the whole, the overall difference in economic development of different regions of the YREB is gradually decreasing (Wu et al. 2017).

While maintaining sustained economic growth, it is necessary to prevent and avoid water pollution and achieve efficient use of water resources. This is an objective requirement for the YREB to solve the water resource crisis and realize the sustainable development (Yang and $\mathrm{Xu}$ 2020; Yang et al. 2015). Based on the analysis of the comprehensive level of water pollution control capacity system in 11 regions of the YREB, the comprehensive level of water pollution control capability system presented a trend of fluctuating growth. The results showed that the water pollution control capability in the YREB had significant spatial variability and regional imbalance. From 2006 to 2019, the water pollution control capability showed this pattern, eastern regions (6.93) $>$ western regions $(6.57)>$ central regions $(6.51)$. In addition, this paper finds that although the water pollution control capability of the YREB is increasing year by year, non-point source pollution control capability and water conservation capacity is relatively low and unstable (Fig. 4b). This means that the prevention and treatment of water pollution in each region of the YREB mainly focuses on industrial pollution, while agricultural non-point source pollution and water conservation are less involved (Sun and Cheng 2019). In recent years, 
agricultural non-point source pollution has become a major challenge with the development of rural economy

(Xiao et al. 2019). Based on these findings, the government should focus on non-point source pollution and water conservation when drafting any ecological protection plans.

\subsection{Spatial-temporal Characteristics Analysis}

The improved CCD model was employed to explore the coordination levels between economic development and water pollution control capability systems in the YREB. In the spatial characteristics aspect, in the eleventh Five-Year Plan, the CCD values of the two systems in the eastern region was higher than that in the central and western regions, and this finding was similar to previous studies by Jiang et al. (2019). In this stage, the CCD values in the central and western regions are in the unbalanced development and transitional development state mainly because of their lagging economic development. Then, with the continuous development of the western regional development strategy, the spatial differences of the 11 regions are gradually narrowing.

From the perspective of temporal evolution trends, the coordination level between the two systems was initially moderately unbalanced development and barely unbalanced development, but this improved rapidly during the eleventh Five-Year Plan. This was followed by a period of favorably balanced development state with steady growth during the twelfth Five-Year Plan, and finally a period of superiorly balanced development with slow growth during the thirteenth Five-Year Plan. From 2006 to 2019, the coupling coordination level between the two systems in all regions of the YREB experienced three stages: unbalanced development, transitional development, and balanced development. This revealed that the coordination between economic development and water pollution control capability systems in the YREB is constantly improving and the spatial difference is gradually narrowing. The important reason is that China has implemented many ways to promote coordinated economic and environmental development in the YREB during the twelfth and thirteenth Five-Year Plan period, such as (i) Issuing policy documents Guidelines of The State Council on Promoting the Development of the Yangtze River Economic Belt by relying on Golden Waterways, (ii) promulgating the programmatic document Outline of the Development Plan for the Yangtze River Economic Belt on the major national strategy for promoting the development of the YREB, and (iii) publishing the notification Ecological and Environmental Protection Plan for the Yangtze River Economic Belt. These documents provided corresponding water environment treatment measures and economic development direction to improve the comprehensive level of the two systems (Huang et al. 2021). Overall, as the YREB has been identified as one of the three national development strategies, the relationship between the two systems has been strengthened, and the coordination levels of systems showed a trend of continuous optimization. 
According to the result analysis of subsystem obstacle factors of economic development and water pollution

control capability, this study found that economic product and waste water treatment capacity, and non-point source pollution control capability is the three main obstacle subsystems. Residents living subsystem and water conservation capacity subsystem have the least impact on CCD of the two systems. In addition, the top five obstacle factors in the two system indicators are basically in the three main obstacle subsystems. Therefore, this study mainly focused on the top-ranking obstacle indicators of each system for in-depth discussion.

In the economic development system, this study mainly discussed these major obstacle indicators, gross product of tertiary industry (E3), per capita gross domestic product (E4), total investment in fixed assets (E7), and annual per capita disposable income of urban households (E12). The increase of E3 is the most significant factor promoting the overall economic development of the YREB, and the promotion effect is the most significant (Cai et al. 2019). In addition, E3 has a significant positive role in promoting urban environmental innovation capacity in the YREB, which can reduce the emission level of various industrial pollution (Bai et al. 2018; Duan et al. 2021; Sun and Cheng 2019). Therefore, the YREB should vigorously develop the tertiary industry (Liang and Wang 2019; Lu et al. 2020). E7 has a great correlation with economic development (Xu 2015). It is precisely because of the continuously increasing proportion of investment in fixed assets that Chinese economy has realized rapid development to a certain extent. Also, E7 has an important impact on the environmental quality of a region (Liu et al. 2017). E4 and E12 are both a standard to measure the living standards of people and important indicators to reflect the overall economic activity in this region (Zhong et al. 2021). Therefore, the formulation of economic development policies should pay special attention to the improve of indicators E3, E4, E7, and E12.

In the water pollution control capability system, these major obstacle indicators were discussed in this study, waste water treatment rate (W1), length of drainage pipes (W2), total volume of waste water treated (W4), and per daily volume treated of sewage treatment facilities (W5). Drainage pipes is an important engineering facility for water pollution control and environment protection (Cheng et al. 2012). Industrial wastewater, domestic wastewater and municipal wastewater must be collected and treated reasonably before being discharged into the natural environment, so that the water environment can be properly treated from the root and people's quality of life can be improved. Drainage pipes is the indispensable material basic to guarantee people's life and social production for modernization, and has become one of the constraints of economic development (Qiu et al. 2011; Wan et al. 2012). W2 is also the key to the efficient operation of sewage treatment facilities. In addition, higher W5 can quickly treat sewage and recycle it, reducing the consumption of water resources for China's production. Accordingly, Higher W1 and W4 mean that most of the production and domestic sewage in the region will be treated, which can basically recover the deterioration of river and lake water ecology ( $\mathrm{Li}$ et al. 2020). A green, 
safe, and pleasant water ecological environment can be preliminarily realized. Therefore, improving W1, W2, W4, and W5 indicators is the key way to improve water pollution control capability.

\section{Conclusions and Policy Implication}

The YREB is a highly influential economic belt and an innovative demonstration belt for the protection and restoration of ecological and environmental systems. Therefore, it is of great significance to analyze the coupling coordination levels of YREB regions between economic development and water pollution control capability. Firstly, this study constructed comprehensive index systems of economic development and water pollution control capability. Secondly, this study examined the CCD values and spatiotemporal differentiation between the two systems in the 11 regions of the YREB from 2006 to 2019. Thirdly, the obstacle degree model was used to diagnose the major obstacle subsystems and indicators. The four main conclusions are as follows:

(1) Through the nonlinear fitting of economic development and water pollution control capability systems in upward trend with the rapid development of economy.

(2) Due to the geographical advantages and the Chengdu-Chongqing Area Twin-City Economic Circle in the YREB, this paper found the J-shaped relationship between the two systems. These results showed that the fitting accuracy is good. That is, the comprehensive level of water pollution control capability presented an

(2) Due to the geographical advantages and the Chengdu-Chongqing Area Twin-City Economic Circle in China, the regions with rapid growth in the comprehensive level of economic development are mainly distributed in the Yangtze River Delta (Shanghai, Zhejiang, Jiangsu), the central cities (Chongqing) and the regions where important cities are located (Sichuan). Moreover, for water pollution control capability system, it showed this pattern, eastern regions $>$ western regions $>$ central regions.

(3) The spatiotemporal differentiation between systems were analyzed based on the improved coupling coordination degree model. In the spatial characteristics aspect, the CCD values between economic development and water pollution control capability system in eastern China is higher than that in central and western China during the eleventh Five-Year Plan, and then the difference becomes smaller. In term of temporal evolution trend, the coupling coordination level in each region of the YREB experienced three stages of unbalanced development, transitional, and balanced development from the eleventh to the thirteenth Five-Year Plan period.

(4) It is found that economic product and waste water treatment capacity, and non-point source pollution control capability are the main subsystems of the obstacles. Residents living subsystem and water conservation capacity subsystem have the least impact. In the indicator level, gross product of tertiary industry (E3), per capita gross domestic product (E4), total investment in fixed assets (E7), annual per capita disposable income of urban households (E12), waste water treatment rate (W1), length of drainage pipes (W2), total volume of waste water 
treated (W4), and per daily volume treated of sewage treatment facilities (W5) were the major factors influencing

the coordinated development of economic development and water pollution control capability systems.

The results of the empirical analysis showed that the YREB is on a benign path of coupling coordination development. Based on its development status and the development strategy of the YREB, this paper provided several policy suggestions to promote the sustainable development of the YREB. Firstly, accelerating infrastructure construction in the YREB can shorten economic distances, reduce transportation costs, and promote economic development. At the same time, it can also deepen economic ties between cities and promote the coupled and coordinated development of the YREB. The main measures include promoting systematic management of mainline waterways and improving the function of golden waterways. Also, the government should rationally arrange layout of ports and promote the construction of shipping centers and regional shipping logistics center along the upper reaches of the Yangtze River, so as to develop river-sea combined transport services.Secondly, all regions should seize the moment of development and put the restoration of the water ecological environment of the Yangtze River in a significant position. The government can clarify the spatial management units of optimized development, key development, restricted development and prohibited development in accordance with the positioning of main functional areas. The control of water ecological environment in the YREB needs to break the boundary of administrative divisions and form joint prevention and control of water ecological environment. Finally, with the implementation of the rural revitalization strategy, agricultural non-point source pollution will become a major challenge. Therefore, policymakers should focus on the non-point source pollution and water conservation when formulating ecological protection plans.

The main contributions of the paper are: (1) based on the characteristics of sustainable development of the YREB, this study constructed a two-coupling analysis indicator system including economic development and water pollution control capability, (2) the spatiotemporal differentiation between the two systems was explored in the 11 regions of the YREB during the eleventh, twelfth, and thirteenth Five-year Plan, respectively, and (3) the major factors affecting the coordinated development of economic development and water pollution prevention and control capacity system have been accurately diagnosed, which provided a direction for the sustainable planning of the YREB. Future studies can investigate more research and exploration of cities with distinctive development models.

\section{Declarations}

The manuscript has not been published before and is not being considered for publication elsewhere. The manuscript is ethically approved and all authors agreed to participate in and publish the final manuscript.

\section{References}


Ai, J., Feng, L., Dong, X., Zhu, X., and Li, Y. (2016). Exploring coupling coordination between urbanization and ecosystem quality (1985-2010): a case study from Lianyungang City, China. Frontiers of Earth Science, 10(3), $527-545$.

Bai, L., Jiang, L., Zhou, H., and Chen, Z. (2018). Spatio-temporal Characteristics of Air Quality Index and Its Driving Factors in the Yangtze River Economic Belt: An Empirical Study Based on Bayesian Spatial Econometric Model. Scientia Geographica Sinica, 38(12), 2100-2108.

Brereton, M. (1978). Synergetics: An Introduction - Nonequilibrium Phase Transitions and Self-Organisation in Physics, Chemistry and Biology. Physics Bulletin, 29, 181.

Cai, B., Zhao, W., Li, Z., and Yang, H. (2019). Spatial spillover effects of export-oriented economic development in the Yangtze River Economic Belt. Resources Science, 41(10), 1871-1885.

Cai, J., Li, X., Liu, L., Chen, Y., Wang, X., and Lu, S. (2021). Coupling and coordinated development of new urbanization and agro-ecological environment in China. Science of the Total Environment, 776(7), 1-11.

Cheng, Y., Zhang, Y., Song, Q., Dai, J., and Zhao, X. (2012). Application of Fractal Dimension in Urban Drainage Pipe Network Planning. Research of Environmental Sciences, 25(1), 89-94.

Cui, X., Shen, Z., Li, Z., and Wu, J. (2021). Spatiotemporal evolutions and driving factors of green development performance of cities in the Yangtze River Economic Belt. Ecological Informatics, 66, 1-8.

Cui, X. G., Fang, C. L., Liu, H. M., and Liu, X. F. (2019). Assessing sustainability of urbanization by a coordinated development index for an Urbanization-Resources-Environment complex system: A case study of Jing-Jin-Ji region, China. Ecological Indicators, 96, 383-391.

Deng, C., Li, H., Peng, D., Liu, L., Zhu, Q., and Li, C. (2021). Modelling the coupling evolution of the water environment and social economic system using PSO-SVM in the Yangtze River Economic Belt, China. Ecological Indicators, 129, 1-14.

Deng, M. (2021). Evaluation on the coordinated development of agricultural economy and rural ecological environment in Anhui province. Fresenius Environmental Bulletin, 30(7), 8372-8381.

Ding, L., Zhao, W. T., Huang, Y. L., Cheng, S. G., and Liu, C. (2015). Research on the Coupling Coordination Relationship between Urbanization and the Air Environment: A Case Study of the Area of Wuhan. Atmosphere, 6(10), 1539-1558.

Duan, D., Xia, Q., Zhang, Y., and Gao, X. (2021). Evolution Pattern and Impact Factors of Environmental Innovation in the Yangtze River Economic Belt.Scientia Geographica Sinica, 41(7), 1158-1167.

Fang, X., and Liu, X. (2020). Coordinated development and spatial relationship analysis of energy-economyenvironment in the Yangtze River Economic Belt, China. Fresenius Environmental Bulletin, 29(6), 4769-4776.

Gai, M., Wang, Y., Ma, G., and Hao, H. (2013). Evaluation of the coupling coordination development between water use efficiency and economy in Liaoning Coastal Economic Belt. Journal of Natural Resources, 28(12), 2081-2094.

Han, H., Guo, L., Zhang, J., Zhang, K., and Cui, N. (2021). Spatiotemporal analysis of the coordination of economic development, resource utilization, and environmental quality in the Beijing-Tianjin-Hebei urban agglomeration. Ecological Indicators, 127, 1-13.

Han, H., Li, H., and Zhang, K. (2019). Spatial-Temporal Coupling Analysis of the Coordination between Urbanization and Water Ecosystem in the Yangtze River Economic Belt. International Journal of Environmental Research and Public Health, 16(19), 1-18.

Huang, L. J., Yang, P., Zhang, B. Q., and Hu, W. Y. (2021). Spatio-Temporal Coupling Characteristics and the Driving Mechanism of Population-Land-Industry Urbanization in the Yangtze River Economic Belt. Land-Basel, 10(4), 117.

Jiang, X., Yang, Q., Geng, Q., Wang, X., and Liu, J. (2019). Spatial-temporal Differentiation and Driving Mechanism of Coordinated Development of Ecological-Economic-Society Systems in the Yangtze River Economic Belt. Resources and Environment in the Yangtze Basin, 28(3), 493-504. 
Jiang, Y., Chi, G., and Yan, L. (2011). The Linear Combination Weights Method Based on Maximum Entropy Principle. Operations Research and Management Science, 20(1), 53-59.

Jin, G., Deng, X., Zhao, X., Guo, B., and Yang, J. (2018). Spatiotemporal patterns in urbanization efficiency within the Yangtze River Economic Belt between 2005 and 2014. Journal of Geographical Sciences, 28(8), 1113-1126.

Li, C., Xu, M., Wang, X., and Tan, Q. (2018). Spatial analysis of dual-scale water stresses based on water footprint accounting in the Haihe River Basin, China.Ecological Indicators, 92, 254-267.

Li, H., Lv, L., Zuo, J., Bartsch, K., Wang, L., and Xia, Q. (2020). Determinants of public satisfaction with an Urban Water environment treatment PPP project in Xuchang, China. Sustainable Cities and Society, 60.

Li, H., Xia, Q., Wen, S., Wang, L., and Lv, L. (2019). Identifying Factors Affecting the Sustainability of Water Environment Treatment Public-Private Partnership Projects. Adv Civ Eng, 2019.

Li, N., Shi, M., Zhang, Z., and Chen, Z. (2020). Analysis on policy effects of integration of Yangtze River Economic Belt Based on a multi-regional CGE Model. Chinese Journal of Management Science, 28(12), 67-76.

Li, Y., Li, Y., Zhou, Y., Shi, Y., and Zhu, X. (2012). Investigation of a coupling model of coordination between urbanization and the environment. Journal of Environmental Management, 98, 127-133.

Liang, H., and Wang, C. (2019). Difference Analysis of industrial development on urban sprawl: data based on 104 cities from the Yangtze River Economic Belt. Resources and Environment in the Yangtze Basin, 28(6), 1253-1261.

Liao, M. L., Chen, Y., Wang, Y. J., and Lin, M. S. (2019). Study on the coupling and coordination degree of high-quality economic development and ecological environmet in Beijing-Tianjin-Hebei region. Appl. Ecol. Environ. Res., 17(5), 11069-11083.

Liu, W., Jiao, F., Ren, L., Xu, X., Wang, J., and Wang, X. (2018). Coupling coordination relationship between urbanization and atmospheric environment security in Jinan City. Journal of Cleaner Production, 204, 1-11.

Liu, Y., Hao, Y., and Gao, Y. (2017). The environmental consequences of domestic and foreign investment: Evidence from China. Energy Policy, 108, 271-280.

Liu, Y., Zhang, Z., and Zhang, F. (2019). Challenges for water security and sustainable socio-economic development: a case study of industrial, domestic water use and pollution management in Shandong, China. Water, 11(8), 1-21.

Long, S., and Yang, J. (2020). Economic-ecological system evaluation and carbon emission spatial differentiation in the Yangtze River Economic Belt. Jiangsu Journal of Agricultural Sciences, 36(1), 108-115.

Lu, S., Tang, X., Guan, X., Qin, F., Liu, X., and Zhang, D. (2020). The assessment of forest ecological security and its determining indicators: A case study of the Yangtze River Economic Belt in China. Journal of Environmental Management, 258, 1-15.

Luo, H., Zhou, W., Bai, J., Tang, J., and Yang, A. (2019). Performance evaluation and obstacle degree analysis of water resources management based on GC-TOPSIS Model. Journal of Water Resources and Water Engineering, 30(4), 26-31.

Miao, L., and Sun, Y. (2020). Quantitative analysis of regional economic balance and sustainable development in Yangtze River Delta and Pearl River Delta. Journal of Coastal Research, 570-574.

Nabavi-Kerizi, S. H., Abadi, M., and Kabir, E. (2010). A PSO-based weighting method for linear combination of neural networks. Computers \& Electrical Engineering, 36(5), 886-894.

Nie, X., and Zhang, Z. (2020). Temporal Characteristics of the Coupling Relationship Between Water Resources Environment and Economic Development in Hubei Province. Journal of Irrigation and Drainage, 39(2), $138-144$.

Pan, H., Yang, C., Quan, L., and Liao, L. (2021). A new insight into understanding urban vitality: a case study in the Chengdu-Chongqing Area Twin-City Economic Circle, China. Sustainability, 13(18), 1-19.

Pan, Y., Li, M., Tang, H., Wu, Y., and Yang, Z. (2021). Land Use Transitions under Rapid Urbanization in ChengduChongqing Region: A Perspective of Coupling Water and Land Resources. Land-Basel, 10(8), 1-21.

Peng, B. H., Sheng, X., and Wei, G. (2020). Does environmental protection promote economic development? From the perspective of coupling coordination between environmental protection and economic development. 
Environmental Science and Pollution Research, 27(31), 39135-39148.

Peng, X., Cheng, J., and Fang, C. (2021). Coordinated development of economy,resources and environment in the Yangtze River Economic Belt based on Three Lines and One Order. China Population Resources and Environment, 31(5), 163-173.

Qian, C. (2021). Study on the coordination degree of regional economy-ecological environment coupling in the Yangtze River Economic Zone. Fresenius Environmental Bulletin, 30(11), 12063-12071.

Qiu, H., Luo, J., and Zheng, G. (2011). Investigation and study on rectification countermeasures of urban sewage pipe network. Chinese Journal of Underground Space and Engineering, 7(6), 1258-1262.

Shi, T., Yang, S., Zhang, W., and Zhou, Q. (2020). Coupling coordination degree measurement and spatiotemporal heterogeneity between economic development and ecological environment--Empirical evidence from tropical and subtropical regions of China. Journal of Cleaner Production, 244, 1-11.

Sun, B., and Cheng, Z. (2019). Research on industrial pollution discharge mechanism of market integration: taking the Yangtze River Economic Belt as an example. China Environmental Science, 39(2), 868-878.

Sun, P., and Luo, N. (2021). Comparative Analysis on the Quality of Urbanization Structure of Central Cities in Southwest Economic Core Area of China: Taking Chengdu-Chongqing as Examples. Scientia Geographica Sinica, 41(6), 1019-1029.

Sun, Q., Zhang, X. H., Zhang, H. W., and Niu, H. P. (2018). Coordinated development of a coupled social economy and resource environment system: a case study in Henan Province, China. Environ Dev Sustain, 20(3), 1385-1404.

Tang, D., Li, Z., and Bethel, B. J. (2019). Relevance Analysis of Sustainable Development of China's Yangtze River Economic Belt Based on Spatial Structure. International Journal of Environmental Research and Public Health, 16(17), 1-16.

Tang, Z., Sun, G., Fu, M., Wen, C., and Plenkovic-Moraj, A. (2020). Research on the Industrial Energy Eco-Efficiency Evolution Characteristics of the Yangtze River Economic Belt in the Temporal and Spatial Dimension, China. International Journal of Environmental Research and Public Health, 17(1), 1-17.

Tian, W., and Chen, R. (2014). Coupling coordination of new rural economic development and environmental protection Evolution analysis based on the data of 1999-2012 of all western regions. Guangdong Agricultural Sciences, 41(13), 172-177.

Wan, Y., Li, N., Peng, M., Feng, J., and Dong, L. (2012). Planning of Water Supply and Drainage System for a Small Town in Southern China. China Water \& Wastewater, 28(24), 28-30.

Wang, W., Xu, J., Wang, X., Ji, L., and Qi, C. (2020). Spatiotemporal differentiation of the coupling relationship among modern agriculture,regional economy and ecological environment in the Yangtze River economic belt. Research of Agricultural Modernization, 41(1), 64-74.

Wen, H., and Wen, F. (2019). Coupling and coordination analysis of water resources-economyecological environment in key provinces ofthe Belt and Road. Engineering Journal of Wuhan University, 52(10), 870-877.

Wu, C., Huang, X., Chen, B., Li, J., and Xu, J. (2017). Analysis of Economic and Spatial Linkage and Economic Integration Trend in Yangtze River Economic Belt from Social Network Analysis Perspective. Economic Geography, 37(7), 71-78.

Wu, Y., Lei, G., Lu, C., Zhou, H., and Guan, Y. (2015). Evaluation of Urban Land Use Performance Based on the Improved TOPSIS Model and Diagnosis of Its Obstacle Degree in Daqing. Research of Soil and Water Conservation, 22(4), 85-90.

Xiao, Q., Zhou, Z., and Luo, Q. (2019). HIgh-quality development of agriculture in the Yangtze River Economic Belt in the new ERA: problems and countermeasures. Journal of China Agricultural Resources and Regional Planning, 40(12), 72-80.

$\mathrm{Xu}, \mathrm{S}$., Wu, T., and Zhang, Y. (2020). The spatial-temporal variation and convergence of green innovation efficiency in the Yangtze River Economic Belt in China. Environmental Science and Pollution Research, 27(21), 26868-26881. 
Xu, W. J., Zhang, X. P., Xu, Q., Gong, H. L., Li, Q., Liu, B., and Zhang, J. W. (2020). Study on the Coupling Coordination Relationship between Water-Use Efficiency and Economic Development. Sustainability, 12(3), 1-13.

$\mathrm{Xu}$, Y. (2015). Factor Analysis and Empirical Research on Regional Logistics Demand in Jiangxi Province. Proc., International Conference on Social Science, Education Management and Sports Education (SSEMSE), 813-816.

Yang, C., Zeng, W., and Yang, X. (2020). Coupling coordination evaluation and sustainable development pattern of geoecological environment and urbanization in Chongqing municipality, China. Sustainable Cities and Society, 61, 119.

Yang, G., and Xu, X. (2020). Foundation and Strategy of Well-Coordinated Environmental Conservation and Avoiding Excessive Development in the Yangtze River Economic Belt. Bulletin of the Chinese Academy of Sciences, 35(8), 940-950.

Yang, G., Xu, X., and Li, P. (2015). Research on the construction of green ecological corridors in the Yangtze River Economic Belt. Progress in Geography, 34(11), 1356-1367.

Yang, R., Sun, M., Zhang, L., Zhang, Y., Liu, W., and Li, Y. (2020). Strategic Issues of Ecological Environment Protection in the Yangtze River Economic Belt. Research of Environmental Sciences, 33(8), 1795-1804.

Yao, Z. (2018). Process Evaluation and Path Exploration of Regional Economic Development: Based on the Empirical Data of the Yangtze River Economic Belt 11 Province from 2003 to 2015. Economic Geography, 38(3), 46-52.

Zhang, C., Wang, Q., Chen, J., Gu, F., and Zhang, W. (2011). Evaluation of debris flow risk in Jinsha River based on combined weight process. Rock and Soil Mechanics, 32(3), 831-836.

Zhang, L., Wu, M., Bai, W., Jin, Y., Yu, M., and Ren, J. (2021). Measuring coupling coordination between urban economic development and air quality based on the Fuzzy BWM and improved CCD model. Sustainable Cities and Society, 75, 1-15.

Zhang, R., and Jiao, H. (2015). Coupling and coordinating between economic development and ecological environment in the Pan Yangtze River Delta. Resources and Environment in the Yangtze Basin, 24(5), 719-727.

Zhang, Y., and Liu, H. (2017). Spatial-temporal coupled coordination between urbanization and ecological environment in Yangtze River Economic Belt. Bulletin of Soil and Water Conservation, 37(6), 334-340.

Zhang, Y., Sun, M., Yang, R., Li, X., Zhang, L., and Li, M. (2021). Decoupling water environment pressures from economic growth in the Yangtze River Economic Belt, China. Ecological Indicators, 122, 1-12.

Zhang, Y., and Wang, F. (2021). Coupling and Coordination of Land Ecological Security and Economic Development in Guangdong Province from 2000 to 2018. Research of Soil and Water Conservation, 28(1), 242-249.

Zhang, Z., and Li, Y. (2020). Coupling coordination and spatiotemporal dynamic evolution between urbanization and geological hazards?A case study from China. Science of the Total Environment, 728, 1-12.

Zhao, L., Xu, T., and Xu, C. (2013). Spatial and temporal analysis of economic evolution of the Yangtze River Economic Belt. Resources and Environment in the Yangtze Basin, 22(7), 846-851.

Zhong, Y., Lin, A., Xiao, C., and Zhou, Z. (2021). Research on the Spatio-Temporal Dynamic Evolution Characteristics and Influencing Factors of Electrical Power Consumption in Three Urban Agglomerations of Yangtze River Economic Belt, China Based on DMSP/OLS Night Light Data. Remote Sensing, 13(6), 1-33.

\section{Funding}

This work was supported by the Fundamental Research Funds for the Central Universities (No. B200207012).

This study would not have been possible without their financial support.

\section{Author Contributions Statement}

L. L. and C.J.: Writing - original draft, Conceptualization, Methodology. L. L. and Z.F. Data curation, Formal analysis. C.J. and Z.F.: Writing - review \& editing. All authors have read and agreed to the published 
676 version of the manuscript.

\section{Data availability}

678 The datasets used and/or analyzed during the current study are available from the corresponding author on 679 reasonable request.

\section{Competing Interests}

681 The authors have no relevant financial or non-financial interests to disclose. 